\title{
EXPLORING THE IMPACTS OF CONSISTENCY IN SOUND MASKING \\ Niklas Moeller
}

KR Moeller Associates Ltd., 3-1050 Pachino Court, Burlington, ON, L7L 6B9

\section{Introduction}

A sound masking system's effectiveness is directly related to its ability to closely match the specified spectrum. Though specifications currently dictate desired levels, they often allow a relatively wide range of spatial variation. To some extent, this leniency is a remnant of the capability of legacy technologies. However, many also assume that these variations do not affect performance to an unacceptable degree.

This paper outlines a series of masking tests and speech intelligibility calculations conducted in an office space. Its purpose is to determine the impacts of inconsistencies in the masking sound and whether general predictive rules can be found.

\section{Method}

Articulation Index values were calculated for field tests, per ASTM E1130-08 ${ }^{1}$. Tests were done for 5 source and 16 listener locations representing varying conditions. Results were converted to comprehension levels, using a transfer function from AI to the percent comprehension of sentences upon first presentation (Figure 1$)^{2}$.

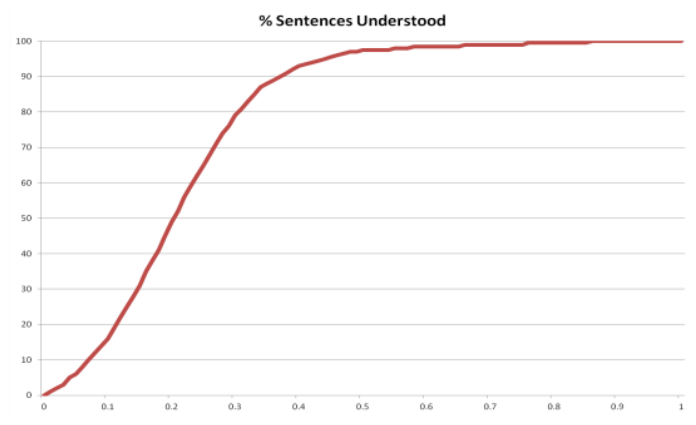

Figure 1: Translation of Articulation Index (horizontal axis) to percent comprehension of sentences on first presentation to listener (vertical axis).

The impact of varying masking levels was analyzed by calculating AI for masking ranging from 42 to $48 \mathrm{dBA}$, in $1 \mathrm{dBA}$ increments. The masking spectrum was held constant at each overall level.

The AI calculation was subsequently investigated for general rules applicable to all site conditions.

\section{Results}

Two representative samples of the sixteen test sets are summarized below (Figures 2 and 3).

In Test A2, the source and listener were in workstations $4.9 \mathrm{~m}$ (16 feet) apart. The unmasked background level was 41.9dBA and AI was 0.367. With masking at $48 \mathrm{dBA}, \mathrm{AI}$ was 0.150 . AI increased to 0.349 with masking at $42 \mathrm{dBA}$. Translated to comprehension, a listener at A2 would understand $31 \%$ of the conversation with $48 \mathrm{dBA}$ of masking and $87 \%$ with $42 \mathrm{dBA}$ of masking. Comprehension increases rapidly as masking decreases. For each $1 \mathrm{dBA}$ decrease in masking, comprehension rose by 6 to $12 \%$, with an average increase of $9.3 \%$.

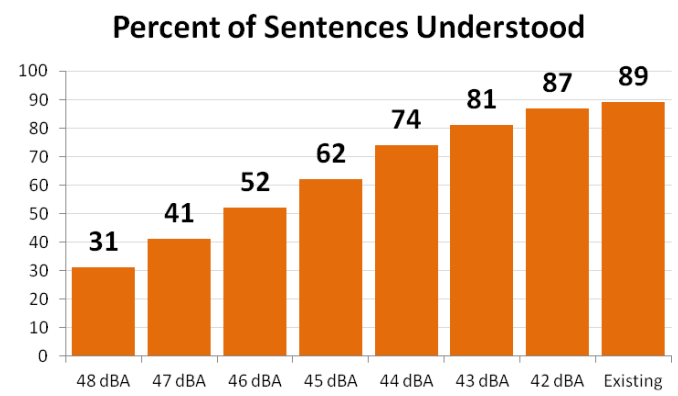

Figure 2: Percent comprehension at location A2 with varying sound masking levels.

In Test B2, the source and listener were in workstations $4.7 \mathrm{~m}$ (15.5 feet) apart. The unmasked background level was $40.6 \mathrm{dBA}$ and AI was 0.339 . With masking at $48 \mathrm{dBA}$ AI was 0.099 . AI increased to 0.296 with masking at $42 \mathrm{dBA}$. A listener in location B2 would understand $14 \%$ of the conversation with $48 \mathrm{dBA}$ of masking and $76 \%$ with $42 \mathrm{dBA}$ of masking. For each 1dBA decrease in masking, comprehension rose by 8 to $14 \%$, with an average increase of $10.2 \%$.

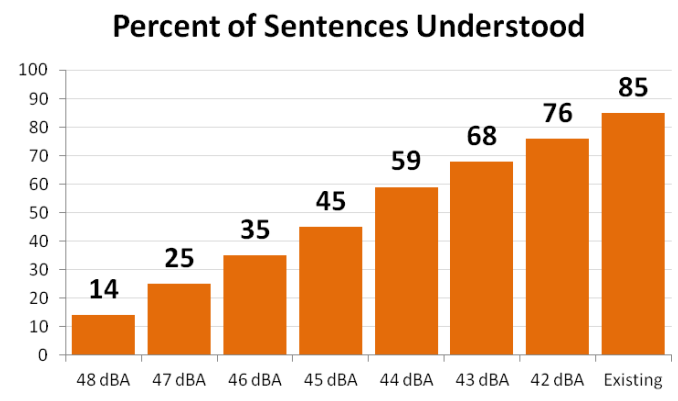

Figure 3: Percent comprehension at location B2 with varying sound masking levels.

\section{Discussion}

System specifications typically state that masking levels be met within set spatial tolerances. A variation of $+/-2 \mathrm{dBA}$ is the most common, giving a 4dBA range. Analysis showed that this range is too broad, given its impact on speech comprehension.

In test $\mathrm{A} 2$, a system specified for $46 \mathrm{dBA}$ would conform if between 44 and 48dBA (Figure 4). However, comprehension over this range rises from $31 \%$ to $74 \%$ - an absolute shift of $43 \%$. In relative terms, comprehension 
where masking is lowest is $239 \%$ of where masking is highest.

\section{Percent of Sentences Understood}

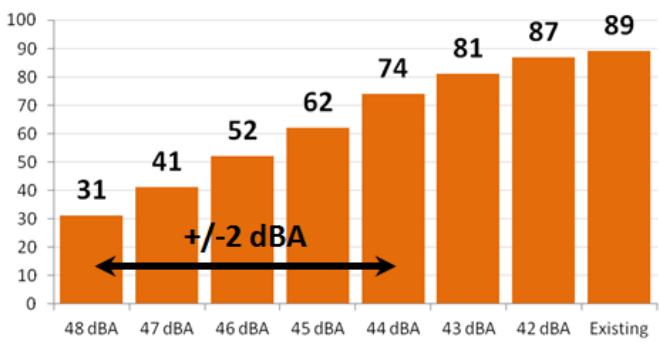

Figure 4: Range of comprehension at $\mathrm{A} 2$ with +/-2dBA masking.

In test B2, masking specified for $45 \mathrm{dBA}$ could vary over a range of 47 to $43 \mathrm{dBA}$ (Figure 5). Comprehension would range from 25 to $68 \%$ - an absolute change of $43 \%$. Speech comprehension at worst is $272 \%$ of that in areas with the highest masking.

Percent of Sentences Understood

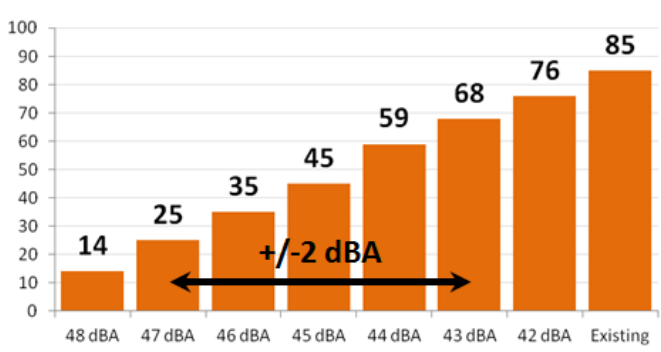

Figure 5: Range of comprehension at B2 with $+/-2 \mathrm{dBA}$ masking.

Similar results were found at varying masking levels and in all of the test scenarios where the source and listener were distant enough for the masking to take effect.

Beyond these location specific results, this study also sought to establish a general rule for the relationship between comprehension and masking level. Analysis of the AI formula demonstrated that one can predict an increase of 0.0333 in AI for each 1dBA decrease in masking level. Each $1 \mathrm{dBA}$ drop in masking yields a $1 \mathrm{dBA}$ increase in the signalto-noise ratio (SNR). When multiplied across the AI band weightings and summed, the result is 0.0333 (Table 1). This holds true so long as the conversation at the listener location is at least $1 \mathrm{~dB}$ above the masking level in each third-octave band used in the AI calculation. If not, the change in AI decreases by the weighted value of any 0 SNR bands.

Thus, one can generally state the relative impact of inconsistency in masking levels without knowing the site conditions. For absolute AI or comprehension levels, site tests are needed; however, for relative comparisons, only tolerances or expected variations are necessary. For example, a system permitting a $4 \mathrm{dBA}$ range allows a $4 \mathrm{x}$ $0.0333=0.1332$ change in AI. A system permitting a $1 \mathrm{dBA}$ range results in a smaller 0.0333 change in $\mathrm{AI}$.

The impact on listeners is better assessed through a conversion to speech comprehension. By analyzing the AIcomprehension transfer function in Figure 1, one finds that, for a given listener, the maximum impact on comprehension from a 0.0333 increase in $\mathrm{AI}$ is $12 \%$. The maximum impact from a 0.1332 increase in $\mathrm{AI}$ is $43 \%$. Comparatively, the more consistent system provides 88 to $100 \%$ masking effectiveness in all areas, while the less consistent system varies from 57 to $100 \%$.

Results show that if a sound masking system were to vary spatially by more than the $+/-2 \mathrm{dBA}$ considered above, the impact on speech comprehension would be even greater.

\begin{tabular}{cc} 
Frequency Band & Al Weighting \\
\hline 200 & 0.00040 \\
\hline 250 & 0.00100 \\
\hline 315 & 0.00100 \\
\hline 400 & 0.00140 \\
\hline 500 & 0.00140 \\
\hline 630 & 0.00200 \\
\hline 800 & 0.00200 \\
\hline 1000 & 0.00240 \\
\hline 1250 & 0.00300 \\
\hline 1600 & 0.00370 \\
\hline 2000 & 0.00380 \\
\hline 2500 & 0.00340 \\
\hline 3150 & 0.00340 \\
\hline 4000 & 0.00240 \\
\hline 5000 & 0.00200 \\
\hline TOTAL & 0.03330 \\
\hline
\end{tabular}

Table 1: Band weightings used in Articulation Index calculation.

There are several additional observations from this study that merit further attention in future papers.

\section{Conclusion}

The impact of varying masking levels on speech comprehension is significant and not commonly appreciated. This finding strongly argues for a tightening of traditionally-accepted tolerances for spatial uniformity.

The comparative performance of masking systems in terms of their effect on speech comprehension can be quantified without considering site conditions once the specified or expected variation in masking level is known.

\section{References}

[1] ASTM E1130-08 Standard Test Method for Objective Measurement of Speech Privacy in Open Plan Spaces Using Articulation Index.

[2] ANSI S3.5-1969(R1986) Methods for Calculation of the Articulation Index, Figure 15. 